\title{
1 Monitoring Indoor Exposure to Combustion-Derived 2 Particles using Plants
}

3

4 Katrien Witters ${ }^{a}$, Michelle Plusquin $^{a}$, Eli Slenders ${ }^{b, 1}$, Imran Aslam ${ }^{c}$, Marcel Ameloot ${ }^{b}$, Maarten

5 B.J. Roeffaers ${ }^{c}$, Jaco Vangronsveld ${ }^{a}$, Tim S. Nawrot ${ }^{a, d}$, Hannelore Bovéa,b,*

$6{ }^{a}$ Centre for Environmental Sciences, Hasselt University, Agoralaan Building D, 3590 Diepenbeek, 7 Belgium

8 b Biomedical Research Institute, Hasselt University, Agoralaan Building C, 3590 Diepenbeek, 9 Belgium

$10{ }^{\mathrm{c}}$ Centre for Surface Chemistry and Catalysis, Leuven University, Celestijnenlaan 200f-box 2461, 113001 Leuven, Belgium

$12{ }^{\mathrm{d}}$ Department of Public Health and Primary Care, Leuven University, Herestraat 49 box 706, 3000

13 Leuven, Belgium

14

\footnotetext{
${ }^{1}$ Eli Slenders, Molecular Microscopy and Spectroscopy, Istituto Italiano di Tecnologia, Via Enrico Melen 83, 16152 Genua, Italy.

*Corresponding author. Centre for Environmental Sciences, Hasselt University, Agoralaan Building D, 3590 Diepenbeek, Belgium. Email addresses: hannelore.bove@uhasselt.be (H. Bové).
} 
21 Indoor plants can be used to monitor atmospheric particulates. Here, we report the label-free

22 detection of combustion-derived particles (CDPs) on plants as a monitoring tool for indoor

23 pollution. First, we measured the indoor CDP deposition on Atlantic ivy leaves (Hedera hibernica)

24 using two-photon femtosecond microscopy. Subsequently, to prove its effectiveness for using it as

25 a monitoring tool, ivy plants were placed near five different indoor sources. CDP particle area and

26 number were used as output metrics. CDP values ranged between a median particle area of

$270.45 \times 10^{2}$ to $1.35 \times 10^{4} \mu \mathrm{m}^{2}$, and a median particle number of $0.10 \times 10^{2}$ to $1.42 \times 10^{3}$ particles for the

28 indoor sources: control (greenhouse) $<$ milling machine $<$ indoor smokers $<$ wood stove $<$ gas

29 stove < laser printer. Our findings demonstrate that Atlantic ivy, combined with label-free

30 detection, can be effectively used in indoor atmospheric monitoring studies.

\section{$31 \quad$ Main finding}

32 Two-photon femtosecond microscopy can be used to selectively measure the deposition of 33 combustion-derived particles on indoor plants at different exposure levels.

\section{Keywords}

35 Indoor pollution; Combustion-derived particles; Monitoring; Ivy 


\section{Introduction}

Indoor air quality is an essential determinant of healthy life and well-being, especially since

42 people are spending a large amount of time indoors. Indoor concentrations of air pollutants can

43 significantly increase when important sources of pollutants are present (Bott, 2000; Myers and

44 Maynard, 2005). Particulate matter (PM) is an important indoor pollutant of particular concern

45 with regard to adverse health effects. The EU Directive 2008/50/EC recognized that there is no

46 identifiable threshold for PM exposure below which it would not pose a risk to human health

47 (European Parliament Council of the European Union, 2008), and the 2013 recommendation of

48 the International Agency for Research on Cancer (IARC) identified the PM mixture as a group 1

49 carcinogen (IARC, 2013). Indoor PM includes both particles of outdoor and indoor origin. Apte

50 and Salvi noted more than 60 sources of indoor air pollution (Apte and Salvi, 2016). The most

51 significant indoor PM sources include fuel used for cooking (Stabile et al., 2014) as well as heating

52 practices (Apte and Salvi, 2016; United States Environmental Protection Agency, 2019), and

53 indoor tobacco smoking (Gerber et al., 2015). Additionally, printers have become common indoor

54 electronic equipment and are high emitters of ultrafine particles (He et al., 2007; Morawska et al.,

55 2019) but also low levels of $\mathrm{PM}_{10}$ and $\mathrm{PM}_{2.5}$ are emitted (Tang et al., 2012). These sources

56 generally generate combustion-derived particles (CDPs). CDPs comprise both engineered carbon

57 black (CB) used in and emitted by numerous consumer products such as printer toners, and black

58 carbon (BC) particles that are emitted as an unwanted by-product during the incomplete

59 combustion of fossil fuels, biofuels and biomass (Center for Climate and Energy Solutions, 2010;

60 Climate and Clean Air Coalition, 2016; Long et al., 2013). Those particles are considered one of

61 the most toxic components of PM (Janssen et al., 2011; Krzyzanowski et al., 2005). Recently, our

62 research group has demonstrated that in real-life conditions BC particles, as part of the CDPs, 
63 translocate from the lungs to different organs as shown by their presence in urine (Saenen et al.,

64 2017) and placental tissue (Bové et al., 2019).

65 Approaches for monitoring air pollution were expensive and required complex equipment,

66 limiting large-scale applicability and accessibility. However, this has changed with the availability

67 of low-cost and easy-to-use air pollution sensors (Snyder et al., 2013). While these detection

68 devices are currently available to monitor the concentrations of gas-phase species or PM in general,

69 no method is readily available for the accurate determination of the CDP fraction in the air

70 pollution mixture. To overcome these challenges, we evaluated the feasibility of the label-free

71 detection of CDPs on indoor plants as a monitoring tool. Already numerous studies have

72 demonstrated the successful use of plant leaves as a monitoring tool of atmospheric PM because

73 of their ability to scavenge and accumulate significant amounts of particulates (Baldacchini et al.,

74 2017; Capozzi et al., 2019; Di Palma et al., 2017; Dzierżanowski et al., 2011; Hofman et al., 2017;

75 Popek et al., 2013; Sæbø et al., 2012). In addition, using plants leaves has been pointed as a rapid,

76 yet reliable approach that enables the collection of site-specific PM. The deposition and

77 accumulation of atmospheric particulates is generally higher with vegetation than with other

78 surfaces such as artificial substrates (Pugh et al., 2012). The accumulation efficiency of leaves

79 varies between plant species, influenced by their phenology (deciduous vs. evergreen) and their

80 micro-morphological characteristics, e.g. wax layer properties, microsurface roughness and

81 presence of trichomes (Popek et al., 2013). For this study, Hedera hibernica or Atlantic ivy was

82 selected as test plant because of its known high capacity to scavenge ambient particulates,

83 evergreen foliage, robustness both indoors and outdoors, presence of stomata and trichomes, and

84 resistance to air pollution (Metcalfe, 2005; Sternberg et al., 2010). By combining these

85 advantageous features with the label-free detection of the deposited CDPs using two-photon 
86 femtosecond microscopy, as recently developed by Bové et al. (Bové et al., 2016), a very unique

87 monitoring approach is presented. This approach allows the direct visualization of CDPs without

88 the need for sample/particle labeling and/or pretreatment, meaning we are not adding fluorophores

89 and, thus, only fluorescent signals from endogenous compounds are possible. In addition, it allows

90 the specific detection of all carbon-based particles including all CDPs independently of their

91 origin/source. After optimizing and validating the quantification of indoor CDP deposition on the

92 indoor green, our developed monitoring tool was employed to evaluate five different indoor

93 sources producing varying CDP concentrations.

\section{2. Materials and Methods}

95

96

97

\subsection{Experimental steps for CDP detection}

Per location (see section 2.3), four exposed leaves from one plant were selected and three biopsies per leave were taken on distinct locations between the largest veins, as shown in Figure 1A, using a sterile scalpel and forceps in a clean room with filtered air (Genano 310/OY, Finland, particle filtration cut-off $>0.003 \mu \mathrm{m}$ ) to prevent any external particulate contamination. Each biopsy was placed and taped on a coverslip (Menzel-Gläser, 24'55 mm, $1.5 \mathrm{~mm}$ ) with the abaxial side facing the glass for inverted imaging (Figure 1B). The CDP deposition on the ivy leaves was identified using a specific and sensitive detection method based on the white light (WL) generation of the particles under two-photon femtosecond illumination, see Figure 1B (Bové et al., 2016). Bové et al. (Bové et al., 2016) observed the WL generation for four different carbon-based particles with diameters ranging from 13 to $500 \mathrm{~nm}$, suggesting that the WL emission under femtosecond near-infrared illumination is a general property of carbon-based particles. Images were collected using a Zeiss LSM 510 (Carl Zeiss, Jena, Germany) confocal laser scanning microscope suitable for non-linear optical imaging, equipped with a two-photon femtosecond pulsed laser (MaiTai 
109 DeepSee, Spectra-Physics, USA; 110 femtoseconds, $80 \mathrm{MHz}, 10 \mathrm{~mW}$ average laser power on the 110 sample or a power density of $1 \times 10^{5} \mathrm{~W} / \mathrm{cm}^{2}$ ) tuned to a central wavelength of $810 \mathrm{~nm}$. WL from

111 the BC particles was acquired in the non-descanned mode, meaning the emission light is directly

112 reflected on the detector, after spectral separation with a $442 \mathrm{~nm}$ dichroic beam splitter and 113 emission filtering employing a $400-410 \mathrm{~nm}$ band-pass filter. The two-photon excited

114 autofluorescence (TPAF) from the leaves was captured using a short pass dichroic $650 \mathrm{~nm}$ beam 115 splitter and a $450-650 \mathrm{~nm}$ bandpass filter to additionally filter the emission light. Within every 116 biopsy, three spots were chosen randomly and a z-stack throughout the whole leaf (intervals of $1176.62 \mu \mathrm{m}$ ) was made for every spot using a 10x/0.3 (Plan-Neofluar) objective (Figure 1C). Per 118 location, four biological repeats and nine technical repeats were made, resulting in $36 \mathrm{z}$-stacks, 119 each with a size of $898.20 \times 898.20 \times 6.62 \mu \mathrm{m}^{3}\left(1.76 \times 1.76 \times 6.62 \mu \mathrm{m}^{3}\right.$ voxel size $)$ and recorded 120 with a $3.09 \mu$ s pixel dwell time.

121 To quantify the CDPs in the acquired z-stacks, a customized and automated Matlab 122 program (Matlab R2017b (9.3.0.713579), MathWorks, Eindhoven, the Netherlands) was used. The 123 program calculates a maximum projection of the z-stack followed by a peak-find algorithm that 124 detects connected pixels with an intensity above a certain threshold value which was set here $1250.03 \%$ lower than the highest pixel intensity value of the images (Figure 1D). This threshold 126 resulted in reproducible results without false positive and/or negative values, which was checked 127 using Fiji (ImageJ v2.0, Open source software, http://fiji.sc/Fiji). The output metrics 'particle 128 area', the total area of the particles in the field of view, and 'particle number', the total number of 129 particles in the field of view, were used for further analysis (Figure 1E). 
To evaluate the differences in CDP deposition in relation to the leaf topography at the 132 abaxial and adaxial side, the deposited CDP areas of both sides were analyzed after exposure.

133 The emission fingerprints of the detected CDP particles on the leaves and TPAF from the

134 leaves were recorded using a Zeiss LSM 880 confocal laser scanning microscope suitable for non-

135 linear optical imaging equipped with the same two-photon femtosecond pulsed laser as described

136 for the LSM 510 system. This setup allowed accurate detection of the emission fingerprint of the

137 particles. Gain and laser power were changed to avoid saturation of the emission signal so that the

138 WL signal could be observed over the range from 410 to $650 \mathrm{~nm}$ : signals were collected in $9.7 \mathrm{~nm}$

139 bins of a QUASAR thirty-two channel GaASP spectral detector (Carl Zeiss, Jena, Germany). The

140 resulting $1024 \times 1024$ lambda image with a pixel size of $0.104 \mu \mathrm{m}$ was detected with a pixel dwell

141 time of $2.05 \mu \mathrm{s}$. The emission fingerprint of commercially available CB nanoparticles (CCB; US

142 Research Nanomaterials, USA) was recorded as a reference using identical settings.

Following femtosecond pulsed laser illumination, the temporal responses of the emitted

144 signals originating from the CDPs on the leaves, from the ivy leaf cells themselves and from 145 reference particles dried on a coverslip were detected using the BiG.2 GaASP detector of the LSM 146880 microscope. The detector was coupled with an SPC 830 card (Becker and Hickl, Germany), 147 which was synchronized to the pulse train of the MaiTai DeepSee laser. Recordings of $256 \times 256$ 148 images with a pixel size of $0.346 \mu \mathrm{m}$ were acquired using a pixel dwell time of $8.19 \mu \mathrm{s}$. The 149 instrument response function (IRF) was determined by detecting the temporal response of the laser 150 pulse using potassium dihydrogen phosphate crystals. The obtained IRF was used for the analysis 151 of all other temporal measurements for curve fitting. Time-correlated single photon counting 152 measurements were captured using SPCM 9.80 software and analyzed using SPCImage 7.3 153 software (Becker and Hickl). 
In Raman spectra, the carbon fingerprint of the deposited particles was much weaker than

155 and indistinguishable from the autofluorescence of the leaves, the leaves were chemically

156 quenched for $2 \mathrm{~h}$ in $0.5 \%$ Sudan Black in methanol. Raman measurements were performed on an

157 inverted optical microscope (TiU, Nikon, Japan) equipped with a piezoelectric stage on a home-

158 built optical platform. Continuous-wave laser light from $488 \mathrm{~nm}$ Argon Ion laser (Spectra-Physics,

159 USA) with an average power of 10 to $15 \mathrm{~mW}$ was reflected by a dichroic mirror (Chroma,

160 ZT488rdc, USA) and focused onto the sample with the objective (60x, Plan Fluor, N.A. 0.85,

161 Nikon, Japan). Raman scattered light from the sample was collected using the same objective and

162 directed to a CCD camera (Newton 920, Andor, UK) equipped with a blazed grating

163 monochromator (IHR-320, Horiba, Japan) with a grating of $1200 \mathrm{~g} / \mathrm{mm}$. The Raman signal passed

164 through the $500 \mathrm{~nm}$ long-pass filter (Chroma, HQ500LP, USA) after a $100 \mu \mathrm{m}$ pinhole for confocal

165 detection. The slit width was set to $2000 \mu \mathrm{m}$. The acquisition time was set to $1 \mathrm{~s}$ with averages of

16650 acquisitions to increase the signal to noise ratio. The data were analyzed and fitted using

167 OriginPro (version 2018b (9.55), USA) and Fityk (version 0.9.8, open-source software,

168 https://fityk.nieto.pl/) (Wojdyr, 2010). The background was corrected for the ivy leaf tissue and

169 reference particles following Cadusch P.J. et al. (Cadusch et al., 2013). The Raman spectra of CB

170 nanoparticles were recorded on dry powder as a reference using identical settings.

1712.3 Study design indoor sources

172 To assess our monitoring tool, five indoor sources with varying CDP concentrations and

173 one control were selected: (1) gas stove (Diepenbeek, Belgium), (2) wood stove (Beringen,

174 Belgium), (3)laser printer (Diepenbeek, Belgium), (4) milling machine (Bilzen, Belgium), (5)

175 indoor smokers (Leopoldsburg, Belgium), (6) control (greenhouse of Hasselt University,

176 Diepenbeek, Belgium). Two plants were placed near each source to ensure a sufficient amount of 
177 leaves usable for analysis, i.e. fully-developed and undamaged (Supplementary Information (SI),

178 Figure S1). Plants were all placed close to (approximately $1 \mathrm{~m}$ ) the CDP source and were exposed

179 for 46 days (19/03/2018-03/05/2018). The exposure period was based on the advice of Hofman et

180 al. (Hofman et al., 2017, 2014) and Hauke et al. (Hauke and Schreiber, 1998) about the minimum

181 and maximum exposure period taking into account leaf senescence as well as the exposure period

182 applied in the study of Gawronska \& Bakera (Gawrońska and Bakera, 2015). The plants were all

183 placed on a spot with indirect sunlight at a height of 1.0-1.5 m. Participants were asked to water

184 the soil of the plants every week and to not touch, dust nor move them. They were also requested

185 to avoid cross-contamination, meaning CDP contribution from the other sources under study. For

186 example, active and/or passive smoking was only allowed for the location where they smoked

187 indoors and this was also the case for the use of gas and/or wood stoves. The living room with the

188 wood stove had a volume of approximately $45 \mathrm{~m}^{3}$, and the joinery where the milling machine was

189 located was approximately $625 \mathrm{~m}^{3}$. The locations of all other sources had a volume of

190 approximately $25 \mathrm{~m}^{3}$. In none of the locations air conditioning nor forced ventilation was used.

191 The gas stove was used daily and is located in a half-open kitchen with the exhaust system right

192 above the cooking stove. The wood stove was used once a week for approximately $4 \mathrm{~h}$ meaning

193 on average 7 times or $28 \mathrm{~h}$ of active burning during the study period. In the joinery, the plants were

194 placed on top of a computer numerically controlled milling machine, which was used daily during

195 working hours. For the location with the indoor smokers, two people smoked each a package of

19620 cigarettes per day. The laser printer (Canon iR Advance C5540i) was frequently used, on

197 average 632 pages were printed each working day during the study period.

$198 \quad 2.4$ Leaf sampling 
Atlantic ivy plants (Hedera hibernica, $\varnothing$ pot $90 \mathrm{~mm}$, all of the same age) were kept in a 200 greenhouse at Hasselt University under controlled conditions (Diepenbeek, Belgium; 60\% air

201 humidity, $15 \mathrm{~h}$ photoperiod, temperature: day $23^{\circ} \mathrm{C}$ and night $18^{\circ} \mathrm{C}$ ) prior to use. On the first day 202 of the experiment, the leaves of the plants were carefully rinsed with sterile magnesium sulfate (10 $203 \mathrm{mM}$, Sigma Aldrich, Belgium) in order to remove as much as possible of the pollution present on 204 the leaves. For each plant, one leaf was removed and taped into a Petri dish with the abaxial side 205 facing up, using sterile forceps (SI, Figure S2). Petri dishes were stored in an airtight box in the 206 dark, at constant temperature and humidity until further analysis, i.e. ten days after collection of 207 the leaves at the locations. These control leaves were used to study the variations in the initial CDP 208 loading on each plant, which was found to be insignificant (data not shown).

209 At the end of the experimental period, four leaves in the middle part of the vertical axis of 210 the plant were removed from one of the two plants, randomly chosen in the case that the leaves of 211 both plants were intact, using sterile forceps and placed in separate Petri dishes. Each leaf was

212 fixed with tape in a Petri dish with the abaxial side facing up, to avoid curling and excessive 213 movement of the leaves, and adherence of particles to the bottom of the Petri dish. Samples were 214 then stored as described previously until further analysis, i.e. ten days after the collection .

\subsection{Statistical analysis}

216 Data was analyzed with GraphPad Prism (version 5.00 for Windows, GraphPad Software,

217 USA). Images were analyzed using Fiji (ImageJ v2.0, Open source software, http://fiji.sc/Fiji).

218 For each indoor source, the CDP particle area and number were expressed as the median 219 and interquartile range $\left(25^{\text {th }}, 75^{\text {th }}\right.$ percentile) obtained from the CDP values of the 36 corresponding 220 Z-stacks. 
Data were not normally distributed, therefore to compare the CDP particle area and number

222 on the indoor plants of the five different indoor sources, a Kruskal-Wallis rank-sum test was

223 applied followed by pairwise comparisons using the Wilcoxon rank-sum test. Multiple testing was

224 accounted for by using a Bonferroni correction (significance level $=0.003$ ) ensuring a control of

225 the family-wise error rate below 0.05. Robustness was analyzed after removal of extreme values

226 identified by being 1.5 times lower or higher than the first and third quartile respectively.

227

228

229

230

231

232 3. Results and Discussion

233

3.1 Optimization of the experimental steps for label-free CDP detection

Our previously established method based on the white-light (WL) generation (i.e. signal ranging over the whole visible spectrum) of CDPs under two-photon femtosecond pulsed laser

236 illumination for the sensitive and specific detection of CDPs was used to study indoor particulate

237 deposition on ivy leaves (Bové et al., 2016). Besides the WL signals originating from the deposited

238 CDPs, the plant tissue generates two-photon excited autofluorescence (TPAF) under the two-

239 photon illumination, which was detected simultaneously. The latter provides useful information

240 on the leaf surface and thickness for determining the spot locations while avoiding veins and the

241 number of z-stack images throughout the leaf tissue. The CDP particles were analyzed based on

242 two features: (i) the WL signals saturate compared to TPAF allowing thresholding of the CDP

243 particles (Figure 1D) and (ii) the WL emission by the CDPs was only captured in a narrow 
244 emission window (400 - $410 \mathrm{~nm}$ ) in which interference from other signals is unlikely. As output

245 metrics, both particle number and particle area were defined (Figure 1E). In summary, a flowchart

246 of the experimental steps is shown in Figure 1. Every step in the experiment was designed and

247 monitored to exclude any external contamination.

Figure 2 clearly shows that the CDPs tend to aggregate/agglomerate on the leaf surface

249 instead of being localized individually. This influences the metric particle number, which should

250 be taken into account when interpreting the data. The CDPs taken up by the leaves/plant also

251 aggregate/agglomerate in the veins of the leaves. Therefore, biopsies were taken between the

252 principal veins of the leaves and other large veins were avoided during imaging. Leaves containing

253 spider webs and/or an excessive amount of dust were identified by visually examining the leaves

254 through the ocular of the microscope and excluded from the study to avoid any influence on the

255 results. The heterogeneity of CDP deposition on the leaves was taken into account. From

256 optimization measurements (data not shown), we found that the acquisition of at least $36 \mathrm{z}$-stacks

257 per indoor source (three spots in three biopsies of four exposed leaves) were necessary to obtain

258 reproducible results.

The particle aggregates/agglomerates on the adaxial and abaxial leaf surfaces were

260 analyzed. At every site, both the particle number and area on the adaxial surface were significantly

261 higher than on the abaxial surface (SI, Figure S3). This may be explained by the distinct

262 morphological traits of both sides of the Atlantic ivy leaves. Atlantic ivy leaves have an undulated

263 topography and their epicuticular wax structures are characterized as platelets. While similar

264 micromorphology and wax structure are observed on both leaf surfaces, a high stomatal density

265 on the abaxial side and absence of stomata on the adaxial side are observed. Also, the abaxial

266 surface contains more trichomes (SI, Figure S4), hair-like structures proven to enhance the 
267 accumulation of ambient particles, than the other side of the leaves (Burkhardt, 2010; Castanheiro 268 et al., 2020; Hofman et al., 2017; Li et al., 2019; Metcalfe, 2005; Muhammad et al., 2019). Due to

269 these differences in morphological traits of both surfaces of the ivy leaves and corresponding 270 dissimilarities in particle deposition, the leaf biopsies were imaged from the abaxial towards the 271 adaxial side.

\subsection{Validation experiments of CDP detection}

Various validation experiments were conducted to confirm the carbonaceous nature of the

275 identified particles on the Atlantic ivy leaves.

First of all, the characteristic features of the emitted WL produced under two-photon

277 femtosecond pulsed illumination and generated by the identified CDP aggregates on the indoor 278 green were verified. As previously described and checked for specificity and sensitivity by Bové 279 et al., and Saenen et al. (Bové et al., 2016; Saenen et al., 2017): (i) the emission fingerprint should 280 stretch over the whole visible spectrum and (ii) the temporal response should be instantaneous. 281 First, the recorded emission fingerprint of the identified CDPs (Figure 3A) shows that indeed the 282 emission signal ranges over the various wavelengths of the visible spectrum. As a reference, the 283 WL signal of commercially CB particles was measured, which confirms the WL emission profile.

284 On the other hand, the emission fingerprint of the TPAF of the leaf consists of a distinct emission 285 peak. Subsequently, the temporal responses of the identified CDP particles, reference particles and 286 TPAF (Figure 3B) were recorded to be 350, 320 and $1470 \mathrm{ps}$, respectively. The temporal responses 287 of the reference and CDP particles are instantaneous and non-resolved from the instrument 
288 response function. These results are consistent with previously obtained results and validate the 289 carbonaceous nature of the identified CDP particles (Bové et al., 2016).

290 Additionally, to confirm the carbonaceous nature of the identified CDPs, Raman spectra 291 from the CDPs on the ivy leaves (Figure 4) and from reference particles (SI, Figure S5) were

292 acquired. Raman spectra of both the CDP and REF particles displayed broad D- and G-peaks

293 typically for carbon-based particles and were located at comparable frequencies (Table S1) 294 (Robertson, 2002).

From the performed validation experiments it can be concluded that the identified CDPs 296 are indeed carbon-based particles and thus the particles of interest. In addition, the proposed 297 technique is specific and sensitive for particles, thereby excluding carbon-containing aromatic 298 compounds. Hence, the developed experimental steps present a unique label-free monitoring tool 299 for the screening of CDPs on indoor leaves.

\subsection{Evaluation of the developed monitoring tool for five sources}

The second general aim of our study was to evaluate the developed monitoring tool 302 comprising the label-free detection of CDP deposition by testing it on Atlantic ivy leaves following 303 indoor particulate pollution.

The obtained results from the different indoor sources are summarized in Figure 5, Table

$3051 \& 2$, and Table S2 \& S3. The median CDP particle area (Figure 5A) of the leaves from the control 306 plant (greenhouse) $\left(0.05 \times 10^{3} \mu \mathrm{m}^{2}\right)$ differed significantly $(\mathrm{p}<0.001)$ from all other sources. The 307 highest CDP particle area was found on the leaves collected from the plant located near the laser 308 printer, where a median particle area of $1.35 \times 10^{4} \mu \mathrm{m}^{2}$ was found. The particle area measured near 
309 the laser printer differed significantly from the particle areas measured near the wood stove $310\left(4.10 \times 10^{3} \mu \mathrm{m}^{2}, \mathrm{p}<0.05\right)$, indoor smokers $\left(2.64 \times 10^{3} \mu \mathrm{m}^{2}, \mathrm{p}<0.01\right)$ and the milling machine 311 (1.60x $\left.10^{3} \mu \mathrm{m}^{2}, \mathrm{p}<0.001\right)$. The median CDP particle area of $7.03 \times 10^{3} \mu \mathrm{m}^{2}$ found in the kitchen with 312 the gas stove differed significantly from the indoor smokers $(\mathrm{p}<0.01)$ and the milling machine $313(\mathrm{p}<0.001)$ Similar results were found for CDP particle number (Figure 5B). The median CDP particle 315 number detected on the leaves of the control plant (greenhouse) $\left(0.01 \times 10^{3}\right.$ particles) differed 316 significantly $(\mathrm{p}<0.001)$ from all other sources. The highest median CDP particle number was found 317 on the leaves from the printer room $\left(1.4 \times 10^{3}\right.$ particles $)$, which differed significantly from the 318 number detected near the milling machine $\left(2.5 \times 10^{2}\right.$ particles, $\left.\mathrm{p}<0.001\right)$, where the lowest number 319 of particles was detected. The median particle CDP particle number found in the kitchen with the 320 gas stove $\left(6.6 \times 10^{2}\right.$ particles $)$ differed significantly from the number detected near the milling 321 machine as well $(\mathrm{p}<0.001)$. There were no significant differences found between the other sources 322 (Figure 5B, Table 2 and SI, Table S3). Robustness analysis was performed removing extreme values, but this did not change the 324 conclusions for particle area (SI, Figure S6A and Table S4) and particle number (SI, Figure S6B 325 and Table S5). In summary, for both particle area and number, the indoor sources can be ranked 326 according to increasing CDP deposition on ivy plants as follows: control (greenhouse) < milling 327 machine < indoor smokers < wood stove < gas stove < laser printer. 329 deposition on the analyzed indoor plants confirmed our expectations. The median CDP particle 330 area and number were the highest for the laser printer, where the printer was intensively used in 
331 an office setting with limited ventilation. Laser printers indeed have been reported to be high

332 emitters of CDPs including CB, which is an important component of printer toner (He et al., 2007;

333 Mitsubishi Chemical, n.d.). In 2007, He et al. (He et al., 2007), demonstrated that approximately

$33440 \%$ of the laser printers tested, did emit submicrometer particles and $27 \%$ of them were high

335 particle emitters. They defined high emitters as printers having a ratio $>10$ for particle

336 concentrations measured immediately after the first printed page, compared to the control, i.e. the

337 background office concentrations. We found that the median CDP particle area detected from the

338 printer was 2 times higher than from the gas stove, which was scored as being the second highest

339 source of CDPs in our ranking. Compared to the control, the median particle area detected for the

340 printer was even 300 times higher. For particle number, the median of the printer was 1.2 and 140

341 times higher than of the gas stove and the control, respectively. Both the gas stove and wood stove

342 include the incomplete combustion of gas and wood, respectively. While higher CDP

343 concentrations are expected from wood burning compared to gas cooking, the slightly higher level

344 in the latter might be due to the fact that the gas cooking stove was used on a daily basis, while the

345 wood stove was only used 7 times for a total of $28 \mathrm{~h}$ during the experimental period. In addition,

346 the living room with the wood stove was larger in volume than the kitchen with the gas stove (45

347 vs. $25 \mathrm{~m}^{3}$ ), which can explain the ranking as well (SI, Figure S7 and Tables S6 and S7). In the case

348 of indoor smoking, high concentrations of CDPs are expected since cigarette smoke contains high

349 amounts of BC, which rapidly increase over the background with statistically significant difference

350 (Ruprecht et al., 2017). Yet, the lower ranking of this source may be attributed to the large volume

351 and well ventilation on a daily basis of the living room in which the plant was located. The plant

352 near the milling machine captured a low amount of CDPs. Although during wood shaving large

353 quantities of PM are produced (Barbosa et al., 2018), it does not include a combustion process and 
354 almost no CDPs are generated and emitted. Normalizing for the volume of the living room with

355 the wood stove, only changed the ranking with the gas stove (SI, Figure S7 and tables S6 and S7),

356 future leaf monitoring studies should take into account the volume and the ventilation of the room

357 wherein the source is located.

While the ranking of the indoor sources was in line with our expectations, we

359 acknowledge that a limitation of our study is that this ranking is based on only one plant at one

360 location for each CDP source. However, our aim was to demonstrate the effectiveness of our

361 proposed monitoring tool and therefore the ranking is only indicative. A second limitation is that

362 the obtained results for the different indoor sources were not validated using real-time measuring

363 equipment that can sample the indoor concentration of BC aerosols. Examples of such real-time

364 equipment include optical measurements using filter-based absorption photometers, such as

365 Aethalometers (Weingartner et al., 2003), particle soot absorption photometers (Bond et al., 1999),

366 and multi-angle absorption photometers (Petzold et al., 2005). Photometers can provide real-time

367 measurements and are therefore highly desirable for detecting short-term peaks in concentrations

368 and tracking sources. However, this method is not uniquely sensitive to BC and only provides an

369 estimation of its mass (Petzold et al., 2013). The light absorption coefficients determined from

370 these methods are often biased since the scattering and absorption properties of particles on the

371 filter are not the same as in the atmosphere (Watson et al., 2005). The conversion of these aerosol

372 light absorption coefficients into a light-absorbing carbon mass concentration requires precise

373 knowledge of the mass-specific absorption cross section which can vary significantly in time and

374 space. The application of this conversion also assumes that BC is the only light-absorbing

375 particulate species present, but cross-sensitivity to mineral dust and organic carbon compounds

376 can influence the outcome (Petzold et al., 2013; Schwarz et al., 2010; Sharma et al., 2017). In 
377 addition, all filter-based optical methods exhibit a filter loading effect that decreases the

378 photometer sensitivity and obtained data require a lot of post-processing to accurately determine

379 the CDP fraction in polluted air (Backman et al., 2017; Drinovec et al., 2014). To avoid additional

380 bias, it is also recommended to use a new filter strip for each sampling campaign, typically one

381 per day. Thus, although various techniques exist to determine CDP content in the air, there is no

382 standard method that generates a consistent and accurate determination of CDPs in polluted air,

383 one of the most toxic fractions of PM. In this study we suggest the use of ivy leaves, which have

384 already shown to be a reliable bio-indicator for PM, as a monitoring tool for CDPs. The deposition

385 efficiency of atmospheric particulates is generally higher to vegetation than to other surfaces due

386 to the micro-morphological attributes of plant leaves that promote the deposition and accumulation

387 of atmospheric particulates on their surface (Pugh et al., 2012). By combining the advantageous

388 features of ivy plants with the label-free detection of the deposited CDPs, we provide a unique tool

389 that can detect and quantify the CDP fraction in the air pollution mixture in a specific and sensitive 390 manner.

\section{4. Conclusions}

392 Our results demonstrate that two-photon femtosecond microscopy can be used to selectively 393 determine the CDP deposition on indoor plants at different exposure levels. Using plants as a 394 biological monitoring tool does not require sophisticated and high maintenance equipment and is 395 particularly suitable for long-term monitoring over large areas. In addition, the ease of sampling, 396 the absence of any necessary expensive technical equipment, and the possibility of determining 397 spatial and temporal trends make plants a very suitable tool. By combining this novel detection 398 approach with the advantageous characteristics of Atlantic ivy in terms of CDP scavenging and 399 accumulation, a plant-based monitoring approach is presented that can discriminate between 
400 different levels of CDPs related to the different user sources. This study can contribute to providing

401 a solution to the demand to improve air quality monitoring thereby enhancing the ability to study

402 the adverse health effects related to indoor air pollutants.

\section{5. Artwork and Figures}

404 Table 1. The median, $25^{\text {th }}$, and $75^{\text {th }}$ percentile of the area $\left(\mu \mathrm{m}^{2}\right)$ of the CDPs deposited on the ivy 405 leaves near the different sources.

\begin{tabular}{llll}
\hline & $\mathbf{2 5}^{\text {th }}$ percentile & Median & $\mathbf{7 5}^{\text {th }}$ percentile \\
Control & $0.01 \times 10^{3}$ & $0.05 \times 10^{3}$ & $0.26 \times 10^{3}$ \\
Milling machine & $0.68 \times 10^{3}$ & $1.60 \times 10^{3}$ & $3.67 \times 10^{3}$ \\
Indoor smokers & $0.93 \times 10^{3}$ & $2.64 \times 10^{3}$ & $8.91 \times 10^{3}$ \\
Wood stove & $1.16 \times 10^{3}$ & $4.10 \times 10^{3}$ & $1.01 \times 10^{4}$ \\
Gas stove & $4.92 \times 10^{3}$ & $7.03 \times 10^{3}$ & $1.27 \times 10^{4}$ \\
Printer & $3.14 \times 10^{3}$ & $1.35 \times 10^{4}$ & $2.55 \times 10^{4}$ \\
\hline
\end{tabular}

Table 2. The median, $25^{\text {th }}$, and $75^{\text {th }}$ percentile of the number of CDPs deposited on the ivy leaves 409 near the different sources.

\begin{tabular}{llll}
\hline & $\mathbf{2 5}^{\text {th }}$ percentile & Median & $\mathbf{7 5}^{\text {th }}$ percentile \\
Control & $0.04 \times 10^{2}$ & $0.01 \times 10^{3}$ & $0.33 \times 10^{2}$ \\
Milling machine & $1.26 \times 10^{2}$ & $2.48 \times 10^{2}$ & $4.88 \times 10^{2}$ \\
Indoor smokers & $1.82 \times 10^{2}$ & $3.74 \times 10^{2}$ & $1.04 \times 10^{3}$ \\
Wood stove & $1.37 \times 10^{2}$ & $4.30 \times 10^{2}$ & $1.20 \times 10^{3}$ \\
Gas stove & $5.21 \times 10^{2}$ & $6.59 \times 10^{2}$ & $1.13 \times 10^{3}$ \\
Printer & $3.41 \times 10^{2}$ & $1.42 \times 10^{3}$ & $2.35 \times 10^{3}$ \\
\hline
\end{tabular}


A

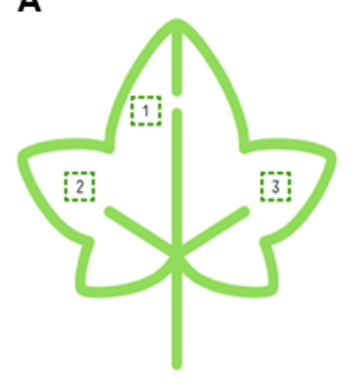

Sample preparation

E
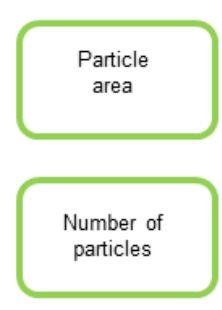

Output
B
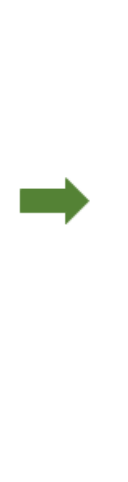

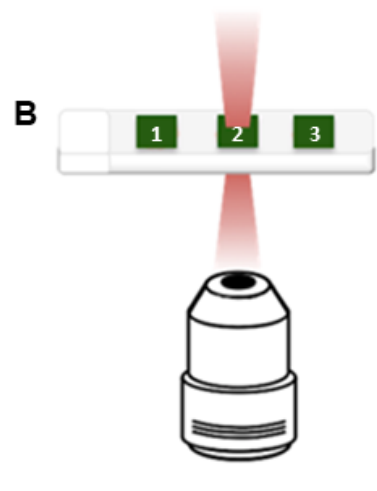

Femtosecond pulsed laser illumination White light emission

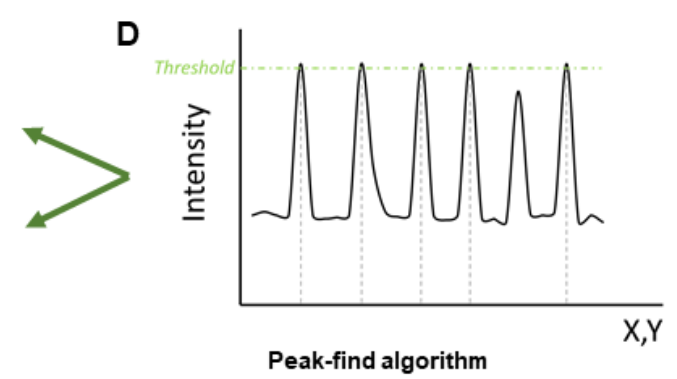

C

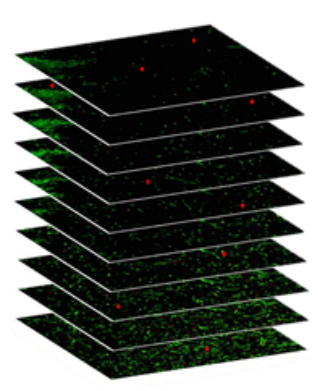

Z-stack at 3 random spots through leaf tissue

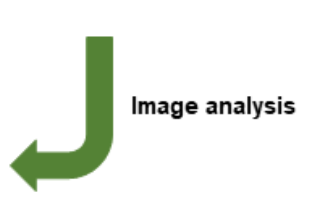

413 Figure 1. Flowchart of the experimental steps for CDP detection on ivy leaves. (A) From four

414 exposed leaves per indoor source, three standardized biopsies were taken on distinct locations

415 between the largest veins of each leaf. (B) The biopsies were taped on cover slides with the abaxial

416 side facing downwards for inverted imaging. The samples were illuminated using a two-photon

417 femtosecond pulsed laser tuned to a central wavelength of $810 \mathrm{~nm}$ (red, $10 \mathrm{~mW}$ radiant power at

418 the sample) using a 10x/0.3 objective at room temperature. (C) WL and TPAF signals generated

419 by the CDPs (red) and leaf tissue (green), respectively, were detected (see materials and methods

420 for detailed experimental steps). In total, $36 \mathrm{z}$-stacks throughout the leaf tissue were taken per 
421 location; three different spots randomly chosen in the three biopsies from four leaves per indoor

422 source. (D) For CDP analysis, a peak-find algorithm counting connected pixels above a threshold

423 value, i.e. $0.03 \%$ lower than the highest pixel intensity value of the images, was used. (E) The

424 output metrics were defined as 'number of particles' and 'particle area'. 2-column fitting image, 425 print in color

426

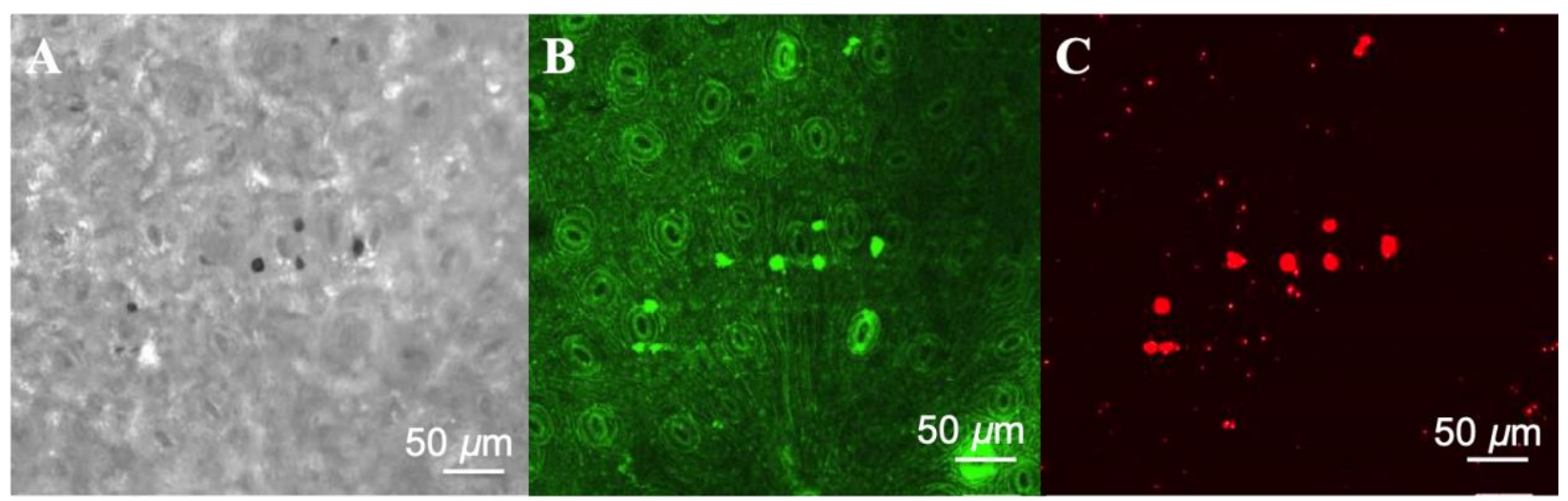

428 Figure 2. Label-free detection of CDP aggregates deposited on the surface an Atlantic ivy leaf 429 using WL generation under femtosecond pulsed laser illumination (10x/0.3 (Plan-Neofluar) 430 objective, excitation $810 \mathrm{~nm}, 80 \mathrm{MHz}, 10 \mathrm{~mW}$ laser power on the sample). (A) Correlative bright

431 field imaging showing the large CDP aggregates as dark spots in the middle of the analyzed abaxial 432 leaf biopsy. (B) Simultaneous detection of the WL signals from the CDP aggregates and the TPAF 433 from the leaf tissue observed at 450-650 nm. (C) Confined detection of the WL signals from the

434 CDP aggregates and single particles observed at 400-410 nm. 2-column fitting image, print in 435 color 
A

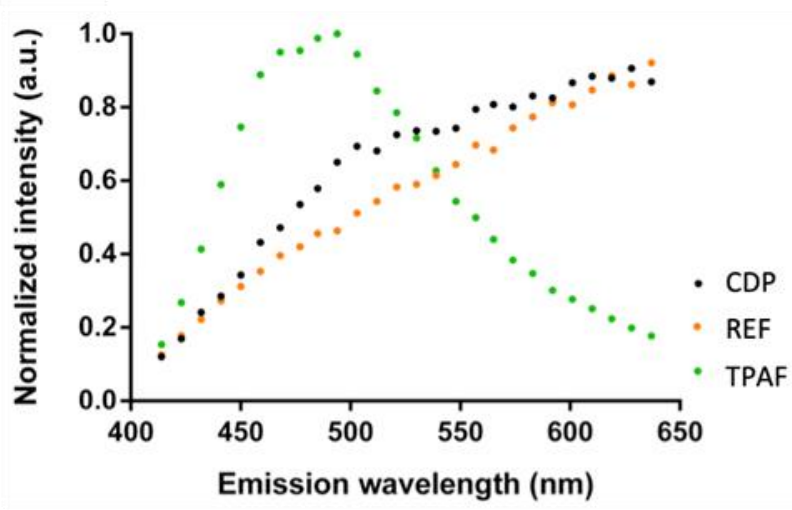

B

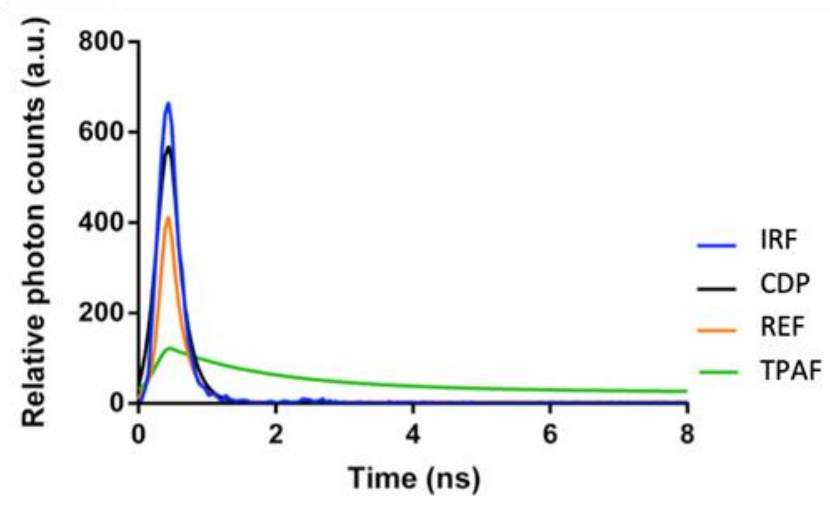

438 Figure 3. Confirmation of the WL characteristics of the identified CDP particles on the ivy leaves.

439 (A) Emission fingerprint of identified combustion-derived particles (CDP), reference carbon black

440 (REF) particles, and two-photon excited autofluorescence (TPAF) under femtosecond pulsed

441 illumination. (B) Temporal response of CDP and REF particles and TPAF measured by time-

442 correlated single-photon counting. The instrument response function (IRF) of the employed

443 microscopic system is shown in blue. Presented data are from one particle (aggregate/agglomerate)

444 measured in one technical and experimental repeat, and representative for the three experimental

445 repeats performed on three randomly chosen samples. 2-column fitting image, print in color 


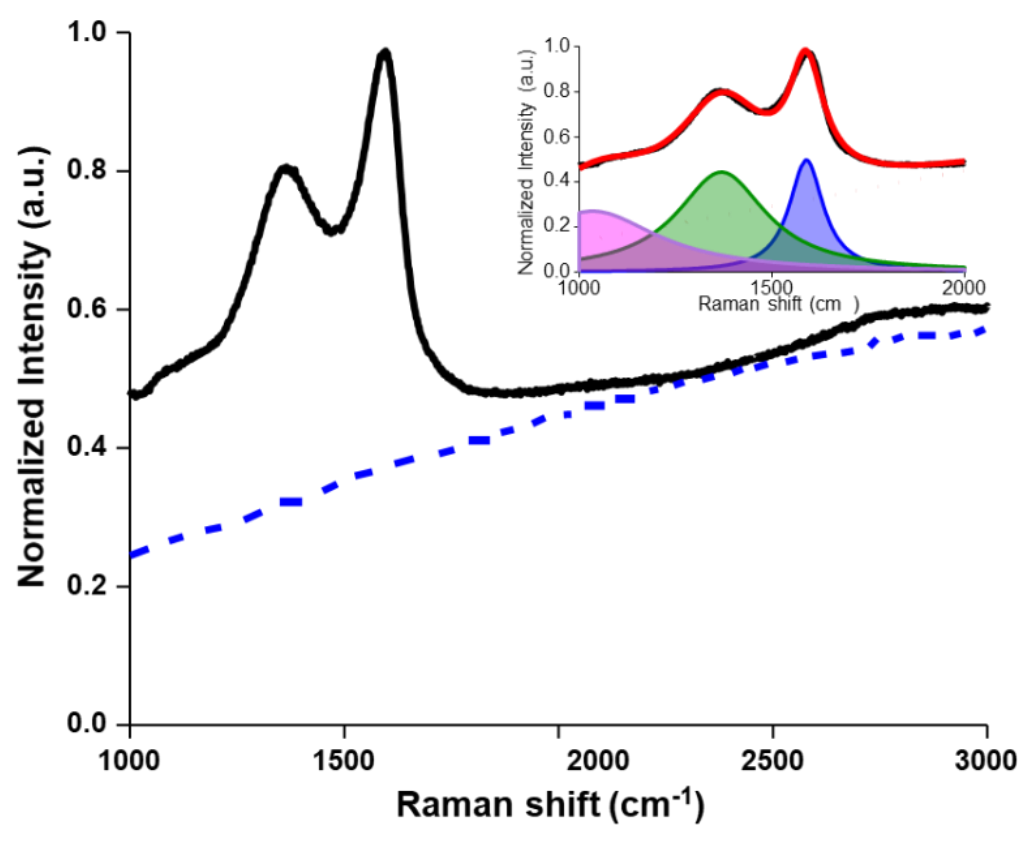

448 Figure 4. Raman spectra (black solid line) from CDPs on an ivy leaf generating an autofluorescent

449 background (blue dotted line). Inset shows the spectra of the CDPs on the leaves (black line), triple

450 Lorentzian line fit (red), spectral components (purple, green and blue lines) fit results for D-(green)

451 and G-bands (blue), and background correction (red dotted line). Summary of fit results can be

452 found in Table S1.1.5-column fitting image, print in color

453 


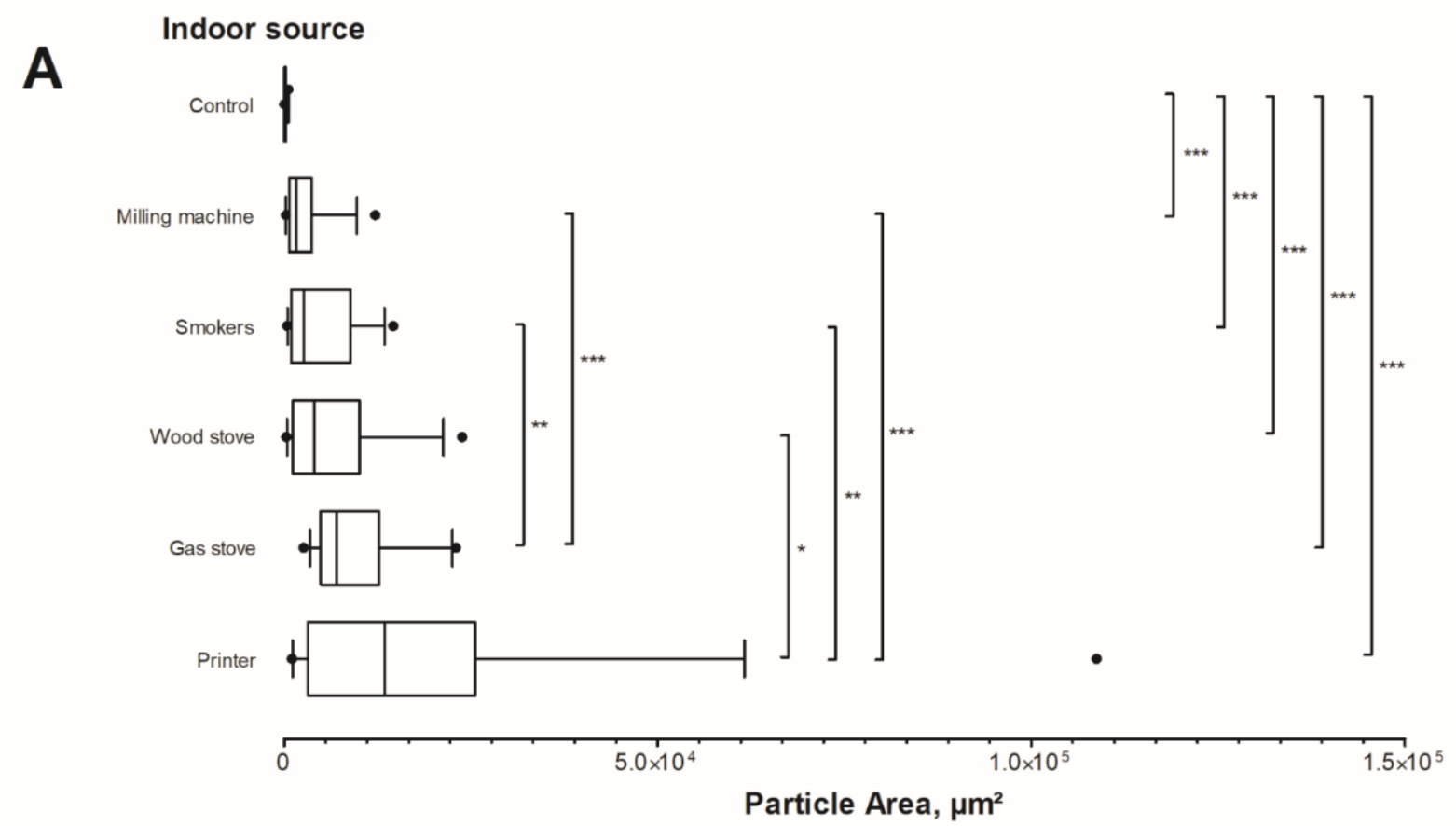

B

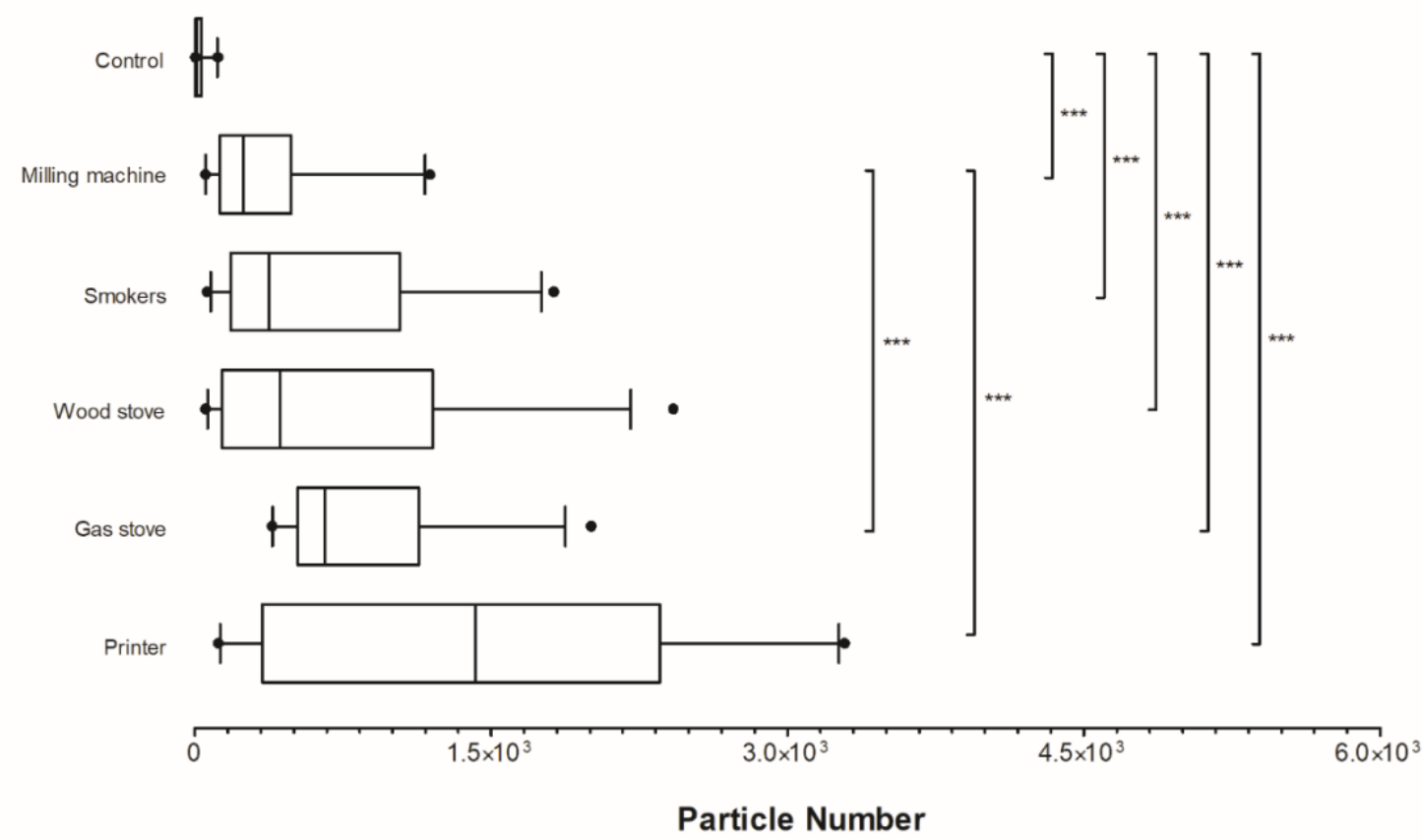

455 Figure 5. Box plots (median, first and third percentiles, interquartile range, and whiskers 456 indicating $95 \%$ of the data) showing (A) the analyzed CDP particle area and (B) the analyzed CDP 457 particle number for the control (greenhouse) $(n=22)$, milling machine $(n=36)$, indoor smokers 
$458(n=36)$, wood stove $(n=36)$, gas stove $(n=36)$, and laser printer $(n=36)$. N indicates the number of 459 analyzed z-stacks per indoor source as a result of four biological and nine technical repeats. Black 460 solid dots represent outliers. $* \mathrm{p}<0.05, * * \mathrm{p}<0.01, * * * \mathrm{p}<0.001$. 2-column fitting image, print in 461 black-white

462

463 


\section{Acknowledgment}

465 The authors thank Mr. E. Slenders for designing the analysis software in Matlab (Matlab R2017b 466 (9.3.0.713579), MathWorks, Eindhoven, the Netherlands).

\section{Funding Sources}

468 The work was supported by the Flemish Scientific Research Foundation (FWO; fellowship H.B. $46912 \mathrm{P} 6819 \mathrm{~N}$ and project G082317N). The detection equipment was funded by the Interuniversity 470 Attraction Poles Program (P7/05) initiated by the Belgian Science Policy Office and the INCALO 471 project (ERC-PoC).

\section{$472 \quad$ References}

473 Apte, K., Salvi, S., 2016. Household air pollution and its effects on health [version 1; peer review: 2 approved]. F1000Research 5. https://doi.org/10.12688/f1000research.7552.1

Backman, J., Schmeisser, L., Virkkula, A., Ogren, J.A., Asmi, E., Starkweather, S., Sharma, S., Eleftheriadis, K., Uttal, T., Jefferson, A., Bergin, M., Makshtas, A., Tunved, P., Fiebig, M., 2017. On Aethalometer measurement uncertainties and an instrument correction factor for the Arctic. Atmos. Meas. Tech. 10, 5039-5062. https://doi.org/10.5194/amt-10-5039-2017

Baldacchini, C., Castanheiro, A., Maghakyan, N., Sgrigna, G., Verhelst, J., Alonso, R., Amorim, J.H., Bellan, P., Bojović, D.Đ., Breuste, J., Bühler, O., Cântar, I.C., Cariñanos, P., Carriero, G., Churkina, G., Dinca, L., Esposito, R., Gawroński, S.W., Kern, M., Le Thiec, D., Moretti, M., Ningal, T., Rantzoudi, E.C., Sinjur, I., Stojanova, B., Aničić Urošević, M., Velikova, V., Živojinović, I., Sahakyan, L., Calfapietra, C., Samson, R., 2017. How Does the Amount and Composition of PM Deposited on Platanus acerifolia Leaves Change Across Different Cities in Europe? Environ. Sci. Technol. 51, 1147-1156. https://doi.org/10.1021/acs.est.6b04052 
Barbosa, R.P., Fiedler, N.C., Silva, J.R.M., Souza, A.P. de, Minette, L.J., Oliveira, M.P., 2018. Concentration and size of airborne particulates in woodworking shops. Rev. Árvore 42. https://doi.org/10.1590/1806-90882018000100009

Bond, T.C., Anderson, T.L., Campbell, D., 1999. Calibration and Intercomparison of Filter-Based Measurements of Visible Light Absorption by Aerosols. Aerosol Sci. Technol. 30, 582-600. https://doi.org/10.1080/027868299304435

Bott, R., 2000. The right to healthy indoor air, WHO meeting. Bilthhoven, The Netherlands. https://doi.org/10.1007/s13398-014-0173-7.2

Bové, H., Bongaerts, E., Slenders, E., Bijnens, E.M., Saenen, N.D., Gyselaers, W., Van Eyken, P., Plusquin, M., Roeffaers, M.B.J., Ameloot, M., Nawrot, T.S., 2019. Ambient black carbon particles reach the fetal side of human placenta. Nat. Commun. 10. https://doi.org/10.1038/s41467-019-11654-3

Bové, H., Steuwe, C., Fron, E., Slenders, E., D’Haen, J., Fujita, Y., Uji-i, H., vandeVen, M., Roeffaers, M., Ameloot, M., 2016. Biocompatible Label-Free Detection of Carbon Black Particles by Femtosecond Pulsed Laser Microscopy. Nano Lett. 16, 3173-3178. https://doi.org/10.1021/acs.nanolett.6b00502

Burkhardt, J., 2010. Hygroscopic particles on leaves: nutrients or desiccants? Ecol. Monogr. 80, 369-399. https://doi.org/10.1890/09-1988.1

Cadusch, P.J., Hlaing, M.M., Wade, S.A., McArthur, S.L., Stoddart, P.R., 2013. Improved Methods for Fluorescence Background Subtraction from Raman Spectra. J. Raman Spectrosc. 44. https://doi.org/10.1002/jrs.4371

Capozzi, F., Di Palma, A., Adamo, P., Sorrentino, M.C., Giordano, S., Spagnuolo, V., 2019. Indoor vs. outdoor airborne element array: A novel approach using moss bags to explore possible 
pollution

sources.

Environ.

Pollut.

249 ,

$566-572$. https://doi.org/10.1016/j.envpol.2019.03.012

511 Castanheiro, A., Hofman, J., Nuyts, G., Joosen, S., Spassov, S., Blust, R., Lenaerts, S., De Wael,

512 K., Samson, R., 2020. Leaf accumulation of atmospheric dust: Biomagnetic, morphological 513 and elemental evaluation using SEM, ED-XRF and HR-ICP-MS. Atmos. Environ. 221, $514 \quad$ 117082. https://doi.org/10.1016/j.atmosenv.2019.117082

515 Center for Climate and Energy Solutions, 2010. What is black carbon? Factsheet. URL https://www.c2es.org/site/assets/uploads/2010/04/what-is-black-carbon.pdf (accessed

Climate and Clean Air Coalition, 2016. Black carbon | Climate \&amp; Clean Air Coalition. Clim. Clean Air Coalit. URL http://www.ccacoalition.org/ru/slcps/black-carbon

Di Palma, A., Capozzi, F., Spagnuolo, V., Giordano, S., Adamo, P., 2017. Atmospheric particulate matter intercepted by moss-bags: Relations to moss trace element uptake and land use.

Drinovec, L., Močnik, G., Zotter, P., Prévôt, A.S.H., Ruckstuhl, C., Coz, E., Rupakheti, M., Sciare, J., Müller, T., Wiedensohler, A., Hansen, A.D.A., 2014. The “dual-spot” Aethalometer: an improved measurement of aerosol black carbon with real-time loading compensation. Atmos.

Dzierżanowski, K., Popek, R., Gawrońska, H., Sæbø, A., Gawroński, S.W., 2011. Deposition of Particulate Matter of Different Size Fractions on Leaf Surfaces and in Waxes of Urban Forest Species. Int. J. Phytoremediation 13 , 1037-1046. https://doi.org/10.1080/15226514.2011.552929

European Parliament Council of the European Union, 2008. Directive 2008/50/EC of the European 
parliament and of the council of 21 May 2008 on ambient air quality and cleaner air for Europe.

534 Gawrońska, H., Bakera, B., 2015. Phytoremediation of particulate matter from indoor air by 535 Chlorophytum comosum L. plants. Air Qual. Atmos. Heal. 8, $265-272$. https://doi.org/10.1007/s11869-014-0285-4

537 Gerber, A., Hofen-Hohloch, A. V., Schulze, J., Groneberg, D.A., 2015. Tobacco smoke particles and indoor air quality (ToPIQ-II) - A modified study protocol and first results. J. Occup. Med. Toxicol. 10. https://doi.org/10.1186/s12995-015-0047-8

540 Hauke, V., Schreiber, L., 1998. Ontogenetic and seasonal development of wax composition and cuticular transpiration of ivy (Hedera helix L.) sun and shade leaves. Planta 207, 67-75. https://doi.org/10.1007/s004250050456

He, C., Morawska, L., Taplin, L., 2007. Particle emission characteristics of office printers. Environ. Sci. Technol. 41, 6039-6045. https://doi.org/10.1021/es063049z

545 Hofman, J., Maher, B.A., Muxworthy, A.R., Wuyts, K., Castanheiro, A., Samson, R., 2017. Biomagnetic Monitoring of Atmospheric Pollution: A Review of Magnetic Signatures from

Hofman, J., Wuyts, K., Van Wittenberghe, S., Samson, R., 2014. On the temporal variation of leaf Biological Sensors. https://doi.org/10.1021/acs.est.7b00832

IARC, 2013. Outdoor air pollution, IARC monographs on the evaluation of carcinogenic risks to humans., Volume 109. ed.

554 Janssen, N.A.H., Hoek, G., Simic-Lawson, M., Fischer, P., van Bree, L., Brink, H. Ten, Keuken, 

an additional indicator of the adverse health effects of airborne particles compared with pm10 and pm2.5. Environ. Health Perspect. https://doi.org/10.1289/ehp.1003369

Krzyzanowski, M., Kuna-Dibbert, B., Schneider, J., 2005. Health effects of transport-related air pollution.

Li, Y., Wang, S., Chen, Q., 2019. Potential of Thirteen Urban Greening Plants to Capture Particulate Matter on Leaf Surfaces across Three Levels of Ambient Atmospheric Pollution. Int. J. Environ. Res. Public Health 16, 402. https://doi.org/10.3390/ijerph16030402

Long, C.M., Nascarella, M.A., Valberg, P.A., 2013. Carbon black vs. black carbon and other airborne materials containing elemental carbon: Physical and chemical distinctions. Environ.

Metcalfe, D.J., 2005. Hedera helix L. J. Ecol. 93, 632-648. https://doi.org/doi:10.1111/j.1365Pollut. 181, 271-286. https://doi.org/10.1016/j.envpol.2013.06.009

Mitsubishi Chemical, n.d. Application Examples of Carbon Black. URL http://www.carbonblack.jp/en/cb/youto.html (accessed 10.26.19).

Morawska, L., Xiu, M., He, C., Buonanno, G., McGarry, P., Maumy, B., Stabile, L., Thai, P.K., 2019. Particle Emissions from Laser Printers: Have They Decreased? Environ. Sci. Technol. Lett. 6, 300-305. https://doi.org/10.1021/acs.estlett.9b00176

Muhammad, S., Wuyts, K., Samson, R., 2019. Atmospheric net particle accumulation on 96 plant species with contrasting morphological and anatomical leaf characteristics in a common $\begin{array}{llll}\text { garden } & \text { experiment. } & \text { Atmos. } & \text { Environ. }\end{array}$ https://doi.org/10.1016/j.atmosenv.2019.01.015

Myers, I., Maynard, R.L., 2005. Polluted air - Outdoors and indoors. Occup. Med. (Chic. Ill). 55, 
Petzold, A., Ogren, J.A., Fiebig, M., Laj, P., Li, S.-M., Baltensperger, U., Holzer-Popp, T., Kinne,

Recommendations for reporting "black carbon" measurements. Atmos. Chem. Phys 13, 8365-8379. https://doi.org/10.5194/acp-13-8365-2013

583

584

585

586

587 588

Petzold, A., Schloesser, H., Sheridan, P.J., Arnott, W.P., Ogren, J.A., Virkkula, A., 2005. Evaluation of Multiangle Absorption Photometry for Measuring Aerosol Light Absorption. Aerosol Sci. Technol. 39, 40-51. https://doi.org/10.1080/027868290901945

Popek, R., Gawrońska, H., Wrochna, M., Gawroński, S.W., Sæbø, A., 2013. Particulate Matter on Foliage of 13 Woody Species: Deposition on Surfaces and Phytostabilisation in Waxes - a 3Year Study. Int. J. Phytoremediation 15, 245-256. https://doi.org/10.1080/15226514.2012.694498

Pugh, T.A.M., MacKenzie, A.R., Whyatt, J.D., Hewitt, C.N., 2012. Effectiveness of green infrastructure for improvement of air quality in urban street canyons. Environ. Sci. Technol. 46, 7692-7699. https://doi.org/10.1021/es300826w

Robertson, J., 2002. Diamond-like amorphous carbon, Materials Science and Engineering: R: Reports. Elsevier. https://doi.org/10.1016/S0927-796X(02)00005-0

Ruprecht, A.A., De Marco, C., Saffari, A., Pozzi, P., Mazza, R., Veronese, C., Angellotti, G., Munarini, E., Ogliari, A.C., Westerdahl, D., Hasheminassab, S., Shafer, M.M., Schauer, J.J., Repace, J., Sioutas, C., Boffi, R., 2017. Environmental pollution and emission factors of electronic cigarettes, heat-not-burn tobacco products, and conventional cigarettes. Aerosol Sci. Technol. 51, 674-684. https://doi.org/10.1080/02786826.2017.1300231

Sæbø, A., Popek, R., Nawrot, B., Hanslin, H.M., Gawronska, H., Gawronski, S.W., 2012. Plant 
species differences in particulate matter accumulation on leaf surfaces. Sci. Total Environ. 427-428, 347-354. https://doi.org/10.1016/j.scitotenv.2012.03.084

Saenen, N.D., Bové, H., Steuwe, C., Roeffaers, M.B.J., Provost, E.B., Lefebvre, W., Vanpoucke, C., Ameloot, M., Nawrot, T.S., 2017. Children's urinary environmental carbon load: A novel marker reflecting residential ambient air pollution exposure? Am. J. Respir. Crit. Care Med.

Schwarz, J.P., Spackman, J.R., Gao, R.S., Perring, A.E., Cross, E., Onasch, T.B., Ahern, A., Wrobel, W., Davidovits, P., Olfert, J., Dubey, M.K., Mazzoleni, C., Fahey, D.W., 2010. The Detection Efficiency of the Single Particle Soot Photometer. Aerosol Sci. Technol. 44, 612628. https://doi.org/10.1080/02786826.2010.481298

Sharma, S., Leaitch, W.R., Huang, L., Veber, D., Kolonjari, F., Zhang, W., Hanna, S.J., Bertram, A.K., Ogren, J.A., 2017. An evaluation of three methods for measuring black carbon in Alert, Canada. Atmos. Chem. Phys 17, 15225-15243. https://doi.org/10.5194/acp-17-15225-2017

Snyder, E.G., Watkins, T.H., Solomon, P.A., Thoma, E.D., Williams, R.W., Hagler, G.S.W., Shelow, D., Hindin, D.A., Kilaru, V.J., Preuss, P.W., 2013. The Changing Paradigm of Air Pollution Monitoring. Environ. Sci. Technol. 47, 11369-11377. https://doi.org/10.1021/es4022602

Stabile, L., Jayaratne, E.R., Buonanno, G., Morawska, L., 2014. Charged particles and cluster ions produced during cooking activities. Sci. Total Environ. 497-498, 516-526. https://doi.org/10.1016/j.scitotenv.2014.08.011

Sternberg, T., Viles, H., Cathersides, A., Edwards, M., 2010. Dust particulate absorption by ivy (Hedera helix L) on historic walls in urban environments. Sci. Total Environ. 409, 162-168. https://doi.org/10.1016/j.scitotenv.2010.09.022 
624 Tang, T., Hurraß, J., Gminski, R., Mersch-Sundermann, V., 2012. Fine and ultrafine particles 625 emitted from laser printers as indoor air contaminants in German offices. Environ. Sci. Pollut. 626 Res. 19, 3840-3849. https://doi.org/10.1007/s11356-011-0647-5

627 United States Environmental Protection Agency, 2019. Indoor Particulate Matter | Indoor Air 628 Quality (IAQ) | US EPA. US EPA. URL https://www.epa.gov/indoor-air-quality-iaq/indoor629 particulate-matter

630 Watson, J.G., Chow, J.C., Chen, L.-W.A., 2005. Summary of Organic and Elemental 631 Carbon/Black Carbon Analysis Methods and Intercomparisons. Aerosol Air Qual. Res. 5, 65102. https://doi.org/10.4209/aaqr.2005.06.0006

633 Weingartner, E., Saathoff, H., Schnaiter, M., Streit, N., Bitnar, B., Baltensperger, U., 2003. 634 Absorption of light by soot particles: Determination of the absorption coefficient by means 635 of aethalometers. J. Aerosol Sci. 34, 1445-1463. https://doi.org/10.1016/S0021$636 \quad 8502(03) 00359-8$

637 Wojdyr, M., 2010. Fityk : a general-purpose peak fitting program. J. Appl. Crystallogr. 43, $1126-$ $638 \quad$ 1128. https://doi.org/10.1107/S0021889810030499 